\title{
Altas habilidades/superdotação na pesquisa brasileira: um estudo sobre as produções nos programas de pós-graduação no Brasil no período de 2002-2020
}

High skills/giftedmess in brazilian research: a study on the productions in postgraduate programs in Brazil in the period of 2002-2020

Altas habilidades/superdotado en la investigación brasilera: un estudio sobre las produciones en los programas de postgrado en Brasil en el período de 2002-2020

\section{Resumo}

Conforme a Política Nacional de Educação Especial na Perspectiva da Educação Inclusiva, publicada em 2008, o alunado especial é constituído por alunos com deficiência, transtornos globais do desenvolvimento e altas habilidades/superdotação. Ainda que sejam muitas as dificuldades de atendimento aos três grupos, elas são ainda maiores na área de altas habilidades/superdotação escassez e divulgação de materiais sobre o tema. Nesse sentido, a pesquisa busca verificar como ele vem sendo pesquisado no Brasil. Para tanto, realizamos um levantamento dos trabalhos produzidos pelos programas de pós-graduação entre 2002 e 2020 e catalogados no banco de dados da Biblioteca Digital Brasileira de Teses e Dissertações, vinculada ao Instituto Brasileiro de Informação em Ciência e Tecnologia, do Ministério da Ciência, Tecnologia e Inovação. Trata-se de uma pesquisa do tipo estado da arte, de cunho bibliográfico e documental e possui caráter descritivo. Após a leitura e análise dos resumos foram selecionadas 108 pesquisas, sendo 24 teses e 84 dissertações, destacando-se 2018 como o ano de maior produção (19\%). Quanto à localização geográfica, há um predomínio da região Sudeste (46\%), seguida pelas regiões Sul (34\%), Norte (9\%), Centro-oeste $(8 \%)$ e Nordeste $(3 \%)$. Os temas mais discutidos foram avaliação, estratégias para atendimento, formação dos docentes, expectativas das famílias, criatividade e inteligências múlltiplas. Os estudos teóricos e os resultados alcançados confirmam a importância da continuidade dos estudos acerca da temática investigada, especialmente no que se refere às políticas educacionais e sua efetivação no contexto escolar.

Palavras-chave: Altas habilidades/superdotação; Inclusão; Estado da arte; Ensino.

\begin{abstract}
According to the National Policy on Special Education from the Perspective of Inclusive Education, published in 2008, the special student body consists of students with disabilities, global developmental disorders, and high skills/giftedness. Although there are several difficulties in treating the three groups, they are even greater in the area of high skills/giftedness due to the scarcity and lack of dissemination of materials on the subject. In this sense, the research seeks to verify how it has been researched in Brazil. To this end, we conducted a survey of the works produced by graduate programs between 2002 and 2020 and cataloged in the database of the Brazilian Digital Library of Theses and Dissertations, linked to the Brazilian Institute of Information in Science and Technology, of the Ministry of Science, Technology, and Innovation. It is a state-of-the-art research, of bibliographic and documentary nature, and it has a descriptive character. After reading and analyzing the abstracts, 108 surveys were selected, of which 24 were theses and 84 dissertations, with 2018 standing out as the year with the highest production (19\%). As for geographic location, there is a predominance of the Southeast (46\%), followed by the South (34\%), North (9\%),
\end{abstract}


Midwest (8\%), and Northeast (3\%). The most discussed topics were assessment, assistance strategies, teacher training, family expectations, creativity, and multiple intelligences. Theoretical studies indicate the need and the results achieved confirm the importance of continuing studies on the subject investigated, especially concerning educational policies and their effectiveness in the school context.

Keywords: High skills/giftedness; Inclusion; Specialized educational assistance; State of art; Research; Teaching.

\section{Resumen}

De acuerdo a la Política Nacional de Educación Especial en la Perspectiva de la Educación Inclusiva, publicada en 2008, el alumnado especial es constituido por alumnos con deficiencia, trastornos globales del desarrollo y altas habilidades/superdotación. Aunque sean muchas las dificultades de atendimiento a los tres grupos, ellas son aún más grandes en el área de altas habilidades/superdotación escasez y divulgación de materiales sobre el tema. En ese sentido, la investigación busca verificar como viene siendo investigado en Brasil. Para tanto, realizamos un levantamiento de los trabajos producidos por los programas de postgrado entre 2002 y 2020 y catalogados en el banco de dados de la Biblioteca Digital Brasileira de Tesis y Disertaciones, vinculada al Instituto Brasileño de Información en Ciencia y Tecnología, del Ministerio de Ciencia, Tecnología y Innovación. Se trata de una investigación del tipo estado del arte, de carácter bibliográfico y documental y posee carácter descriptivo. Tras la lectura y análisis de los resúmenes fueron seleccionadas 108 investigaciones, siendo 24 tesis y 84 disertaciones, destacándose 2018 como el año de mayor producción (19\%). Cuanto a la ubicación geográfica, hay un predominio de la región Sureste (46\%), seguida por las regiones Sur $(34 \%)$, Norte $(9 \%)$, Centro oeste $(8 \%)$ y Noreste $(3 \%)$. Los temas más discutidos fueron evaluación, estratégias para atendimiento, formación de los docentes, expectativas de las famílias, creatividad e inteligencias múlltiplas. Los estudios teóricos e resultados alcanzados confirman la importancia de la continuidad de los estudios acerca de la temática investigada, especialmente en lo que se refiere a las políticas educacionales y su efectuación en el contexto escolar.

Palabras clave: Altas habilidades/superdotación; Inclusión; Atendimiento educacional especializado; Estado del arte; Investigación; Enseñanza.

\section{Introdução}

Em 2019 o número de matrículas na educação básica foi de 47,9 milhões; desse total, 1,3 milhões (2,71\%) são de alunos que compõem o público-alvo do atendimento educacional especializado (AEE), ou seja, alunos com deficiência, transtornos globais do desenvolvimento e altas habilidades/superdotação. (Brasil, 2020a).

Conforme a Política Nacional de Educação Inclusiva (PNEI), publicada em 2008, o AEE deve ser ofertado de forma transversal - complementar ou suplementar - a todas as etapas e níveis do ensino comum, prioritariamente em Salas de Recursos Multifuncionais ou Centros de AEE. (Brasil, 2008).

Desde a publicação da PNEI, as matrículas do alunado especial no ensino comum passaram de $61 \%$ em 2009 para 92,8\% em 2019. Nesse período foram também organizadas e implementadas políticas e práticas pedagógica para esse público; todavia, apesar dos avanços, a área de altas habilidades/superdotação (AH/SD) continua a ser um desafio, especialmente devido às dificuldades de conceituação e identificação desses estudantes e de uma compreensão mais ampla do conceito de diversidade e de arcabouço teórico fundamentado em uma visão de escola voltada para o processo de humanização de todas as pessoas nela inseridas.

Outro limite são os questionamentos sobre a necessidade de atendimento especializado para alunos com AH/SD. Goulart, Mori, Mesti e Albuquerque (2016) explicam que o ensino organizado e mediado promove a aprendizagem e desenvolvimento dos alunos com deficiência e, de modo semelhante, daquelas com habilidades diferenciadas. Para as autoras, crianças não atendidas em suas necessidades educacionais dificilmente desenvolverão suas potencialidades.

Todos os alunos com necessidades educacionais especiais necessitam e têm direito a políticas e práticas especializadas; para tanto, a pesquisa é essencial. Ela possibilita compreender o que já foi produzido sobre determinado tema e como delinear caminhos para ampliar esse conhecimento. O presente estudo busca verificar como o tema vem sendo estudado no Brasil. Para tanto, foi realizado um levantamento e análise dos trabalhos produzidos pelos programas de pós-graduação brasileiros no período de 2002 a 2020 e catalogados no banco de dados da Biblioteca Digital Brasileira de Teses e Dissertações (BDTD, 2021). 
A pesquisa pode ser caracterizada como quali-quantitativa por envolver o que Pereira, Shitsuka, Parreira e Shitsuka (2018) e Severino (2016) definem como discussão analítica de dados quantitativos. De modo mais específico, trata-se de uma pesquisa denominada estado da arte, visto que está voltada para o mapeamento e análise de um conhecimento determinado em um espaço de tempo.

Para Ferreira (2002), o estado da arte tem um caráter bibliográfico, mas avança para além da revisão bibliográfica, pois busca aspectos, dimensões e condições de produção de uma temática em textos acadêmicos diversos. Para a autora, é um proceder metodológico de levantamento, avaliação e síntese de estudos já realizados sobre um assunto.

Para apresentar o percurso metodológico e os resultados alcançados em nossa pesquisa, iniciamos com a fundamentação teórica, abordando AH/SD no contexto da educação inclusiva; na sequência, focamos os procedimentos metodológicos para a coleta e análise de dados.

\section{Altas Habilidades/Superdotação e Atendimento Educacional Especializado}

Goulart et al (2016) apresentam quadros com os principais marcos nacionais e internacionais no atendimento a pessoas com AH/SD; conforme as autoras, em âmbito mundial ele passou a ser mais sistematizado e organizado nos anos iniciais de 1900. Assim como outras áreas da educação especial, a de AH/SD foi impulsionada por movimentos internacionais que originaram documentos como o de Educação para Todos, de 1991 e a Declaração de Salamanca de 1994, os quais conclamaram os países a maior comprometimento com a educação e diversidade. A adesão do Brasil a esse movimento contribuiu para a elaboração do sistema educacional inclusivo.

Em termos específicos, um destaque no atendimento educacional ao aluno com AH/SD é a Lei 5692/71, a primeira a prever ensino especializado para este grupo. Em 1996 essa lei foi modificada e estabeleceu a transversalidade das políticas públicas educacionais em todos os níveis e etapas escolares, bem como o atendimento especializado para os alunos com necessidades educacionais especiais; os AH/SD foram reafirmados como público-alvo.

Como afirma Delou (2007), o conceito vigente associava superdotação e talento, definindo que os alunos com essas características teriam elevada potencialidade, combinada ou isolada, nas capacidades intelectual geral, acadêmica e de liderança, talento especial para artes e pensamento criativo.

$\mathrm{Na}$ perspectiva da educação inclusiva, o conceito adotado envolve aspectos cognitivos, de personalidade e determinantes sociais. Nesse sentido, uma fundamentação básica e atual é a Teoria dos Três Anéis, proposta por Renzulli (2004), para quem a superdotação implica em interação entre três grupamentos de traços: habilidade acima da média de processar e integrar informações e experiências, comprometimento com a tarefa ou persistência e energia e dedicação a determinados temas e criatividade.

Mori e Brandão (2009) explicam que além dos aspectos intelectuais a Teoria dos Três Anéis valoriza a criatividade e comprometimento com a tarefa; o comprometimento e a motivação determinam a característica de perseverança na realização das atividades desafiadoras.

Pérez e Freitas (2016) pontuam outras características comuns nos quadros de AH/SD, tais como:

[...] precocidade, gosto e nível elevado de leitura, interesses variados e diferenciados; tendência a se associar com pessoas muito mais velhas (ou muito mais novas) em lugar de pessoas da mesma idade; capacidade de observação muito diferenciada; assincronismo; preferência por trabalhar ou estudar sozinhos; independência; autonomia; senso de humor refinado e gosto e preferência por jogos de estratégia [...]. (p.13)

De modo divergente às teorias que enfatizam os aspectos individuais, inatos e biológicos do desenvolvimento, Renzulli ressalta a importância das mediações e do processo de escolarização para o desenvolvimento das potencialidades da pessoa com AH/SD. 
Sobre a situação atual das matrículas de alunos com AH/SD, verificamos na Figura 1 um aumento significativo entre 2015 e 2019.

Figura 1: Matrículas de alunos com AH/SD - 2015 a 2019.

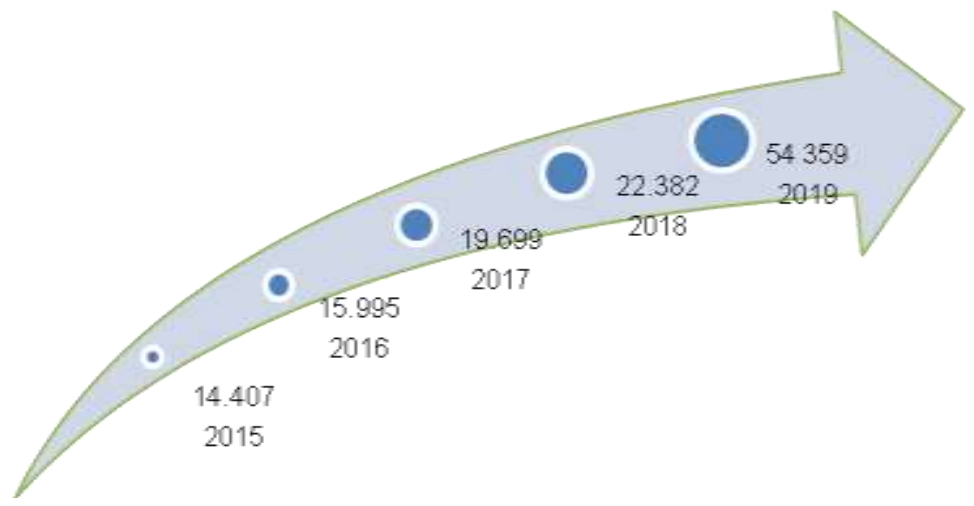

Fonte: Elaboração das autoras com base em microdados do Censo da Educação Básica

A Organização Mundial de Saúde (OMS) estima a porcentagem de 3,5 \% a 5\% de pessoas com AH/SD na população. Assim, apesar de a Figura 1 indicar que o número de matrículas mais que triplicou, ainda assim as matrículas de alunos identificados como com AH/SD representa apenas $0,11 \%$ do total de 47,9 milhões de matrículas na Educação Básica.

A diferença entre o estimado pela OMS e a realidade talvez se deva à dificuldade de o sistema escolar identificar os alunos com as características em pauta. Renzulli (2004) defende a disponibilização de mais serviços educacionais para todos com potencial e criatividade acima da média. De acordo com Virgolim (2014), o autor preconiza o aumento das oportunidades de o aluno desenvolver o pensamento criativo e produzir conhecimentos e produtos que possam impactar e causar mudanças duradouras na sociedade. Enfrentar esse desafio implica em conhecer as características dessa parcela da população escolar e suas necessidades.

Passamos, na sequência, aos dados colhidos e analisados acerca do tema.

\section{Altas Habilidades/Superdotação nos Teses e Dissertações}

A pesquisa tem como foco os estudos sobre altas habilidades nos programas de pós-graduação brasileiros sobre tema altas habilidades. Para tanto, realizamos um levantamento dos trabalhos produzidos pelos programas de pós-graduação entre 2002 e 2020 e catalogados no banco de dados da Biblioteca Digital Brasileira de Teses e Dissertações (BDTD, 2021), vinculada ao Instituto Brasileiro de Informação em Ciência e Tecnologia, do Ministério da Ciência, Tecnologia e Inovação.

Criada em 2002, a BDTD é mantida pelo Instituto Brasileiro de Informações em Ciências Tecnologia - IBICT, com o apoio de Financiadora de Estudos e Pesquisas (FINEP). A plataforma armazena e disponibiliza, de modo eletrônico, teses e dissertações realizadas na pós-graduação.

Para o levantamento utilizamos o unitermo altas habilidades/superdotação, o qual retornou um total de 163 trabalhos, sendo 31 teses e 132 dissertações. Com a leitura dos resumos, constatamos que alguns trabalhos não tratavam do assunto e outros estavam duplicados; por isso, eles foram descartados e o resultado está demonstrado no Quadro 1. 
Quadro 1: Teses e dissertações sobre AH/SD - 2002 a 2020.

\begin{tabular}{|c|c|c|}
\hline Nível & Resultado Inicial & Após a leitura dos resumos \\
\hline Dissertação & 132 & 84 \\
\hline Tese & 31 & 24 \\
\hline Total & 163 & 108 \\
\hline
\end{tabular}

Fonte: Autores.

Como podemos ver no Quadro 1, após a leitura inicial, o conjunto a ser analisado ficou constituído por 108 textos, sendo 84 dissertações $(78 \%)$ e 24 teses (22\%) defendidas em 19 instituições. Na continuidade, os dados foram organizados conforme as seguintes categorias temáticas: distribuição dos trabalhos por nível e ano, instituição de origem e localização geográfica e assuntos tratados.

Quanto à distribuição por nível e ano, os dados da Figura 2 indicam um número baixíssimo de pesquisas até 2010 , variando de um a quatro trabalhos, excetuando os anos de 2003, 2004, 2007 e 2008, nos quais não foram apresentadas defesas com esse objeto. A partir de 2011 há um aumento na produção, com destaque para o ano de 2018, quando foram realizadas 19 pesquisas, ou seja, $18 \%$ do total.

Figura 2: Pesquisa sobre AS/SD por ano.

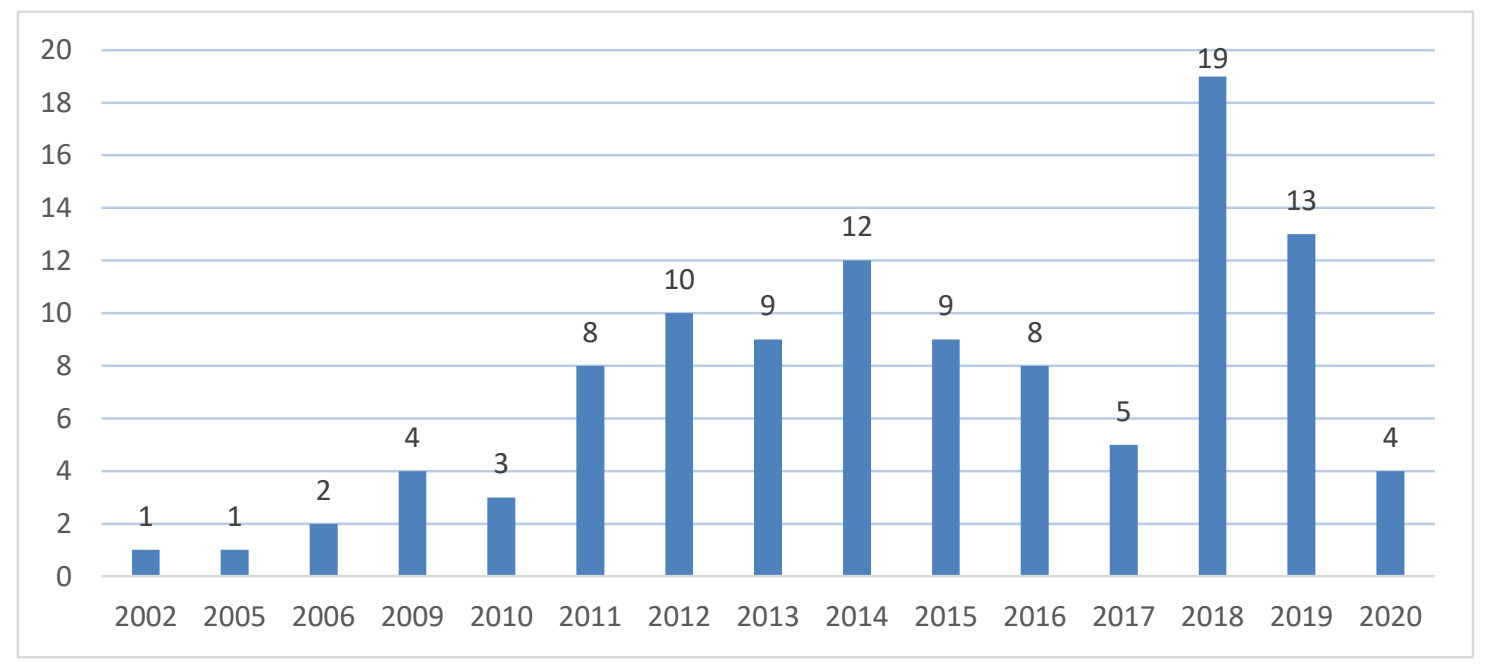

Fonte: Autores.

Como vimos anteriormente, as matrículas de alunos com AH/SD na educação básica está bem distante das projeções da OMS; em 2019 elas chegaram a 54.359, ou seja, 0,11\% do total de matriculados. O esperado seria um índice entre de 3,5 a $5 \%$. Ao relacionar esses dados com os números da Figura 2, processamos que o tema é também pouco estudado. Considerando o período de 2002 a 2020, s três últimos são os que concentram o maior número de trabalhos, ou seja, o assunto passou a ser mais estudado, mas de modo ainda pouco representativo.

Ao averiguar onde são produzidos os estudos, podemos ver na Figura 3 que a maior parte deles está concentrada em instituições da região Sudeste (46\%), seguida pelas regiões Sul (34\%), Norte (9\%), Centro-Oeste (8\%) e Nordeste (3\%). 
Figura 3: Pesquisa sobre AS/SD por região.

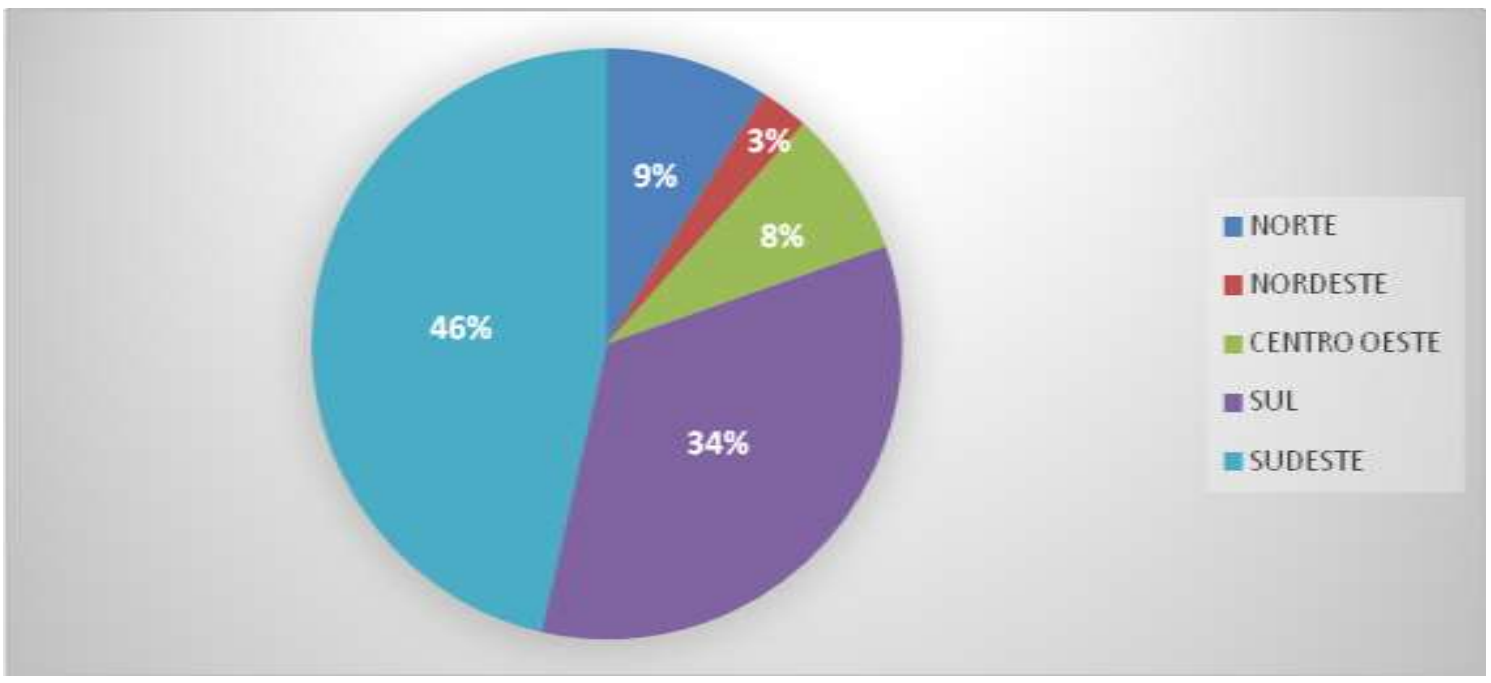

Fonte: Autores.

A concentração dos estudos por região e por instituição fica evidente nas Figuras 3 e 4 . As instituições com mais trabalhos defendidos sobre o tema estão localizadas na Universidade Estadual Paulista (UNESP) e Universidade Federal de Santa Maria; juntas elas somam 45\% da produção total. As demais produções estão localizadas na Universidade de São Paulo (USP, 10), Universidade Federal de São Carlos (UFSCAR, 9), Universidade de Brasília (UNB, 8), Universidade Estadual de Londrina (UEL, 6) e Universidade Federal do Espírito Santo (UFES, 6). As outras teses e dissertações estão localizadas em 12 instituições, com números iguais ou inferiores a cinco defesas realizadas sobre AH/SD.

Figura 4: Pesquisa sobre AS/SD por instituição.

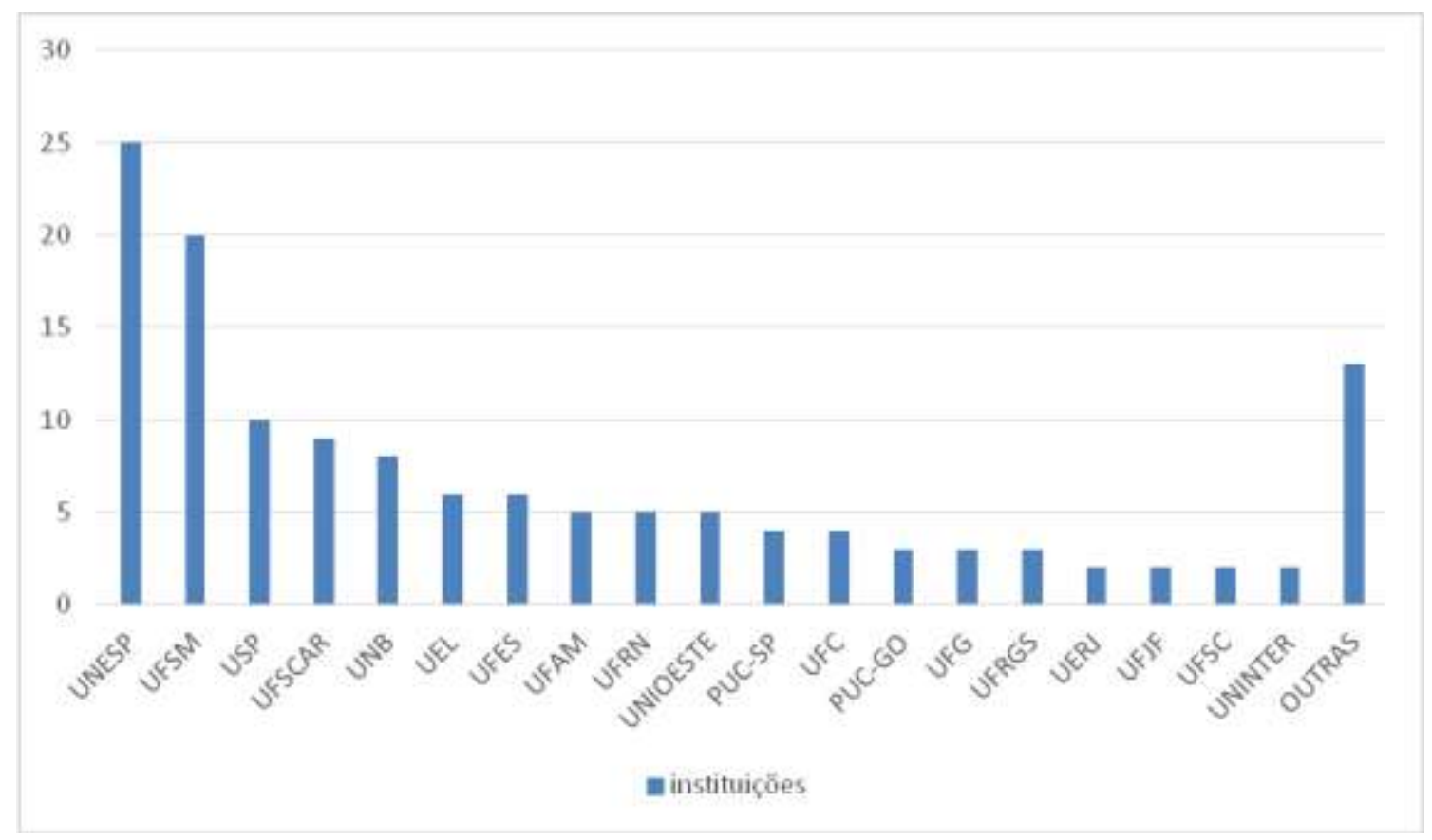

Fonte: Autores.

Além da centralidade por região e universidades, a Figura 4 reafirma a escassez dos estudos. No site da BDTD há 123 instituições cadastradas; em apenas 19 delas foram defendidas teses e dissertações sobre AH/SD.

Com relação aos assuntos abordados nos 108 trabalhos, eles estão classificados conforme demonstrado na Figura 5. 
Figura 5: Assuntos abordados nas pesquisas sobre AS/SD.

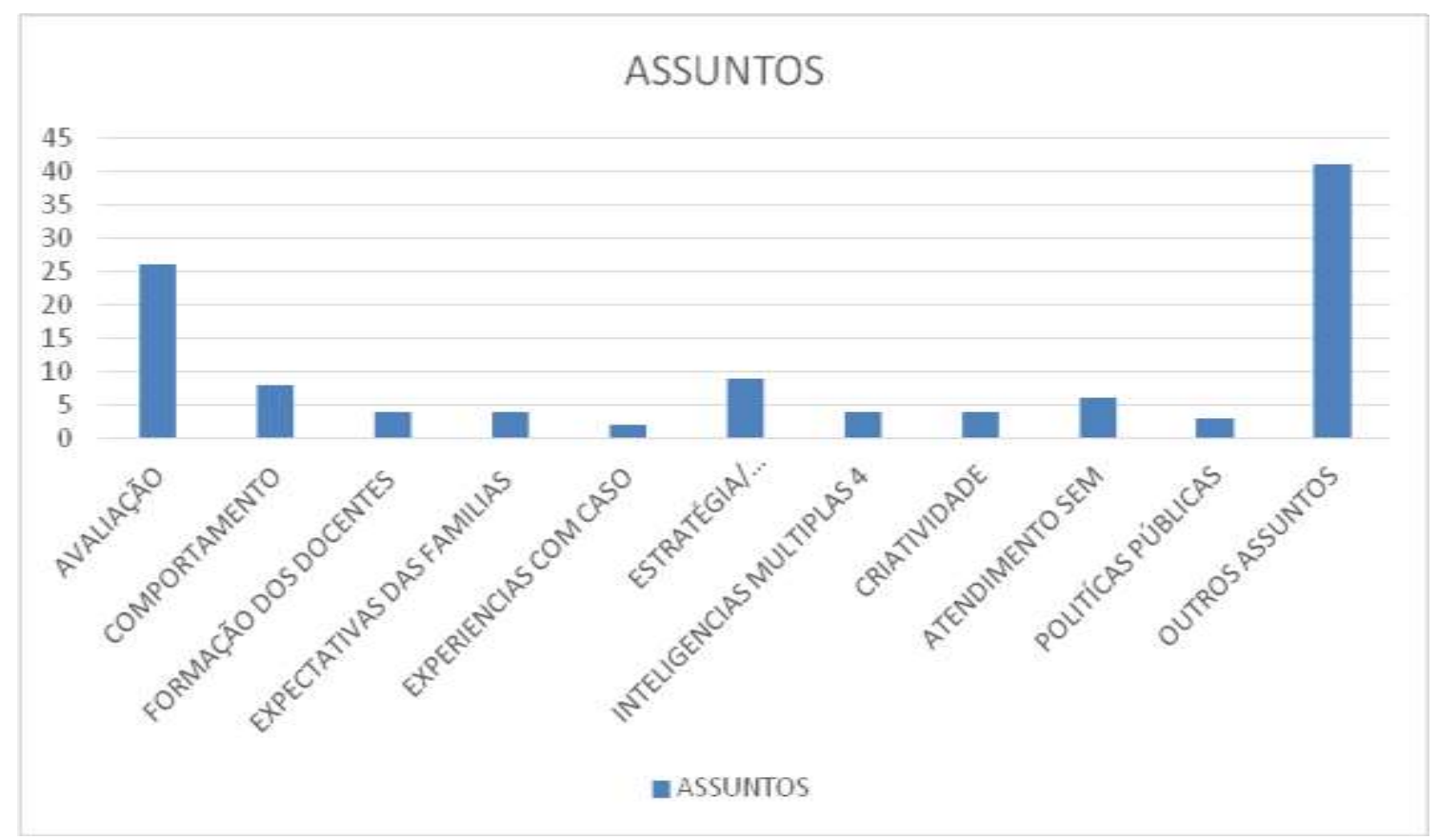

Fonte: Autores.

Como demonstrado na Figura 5, os assuntos mais abordados, em ordem decrescente, foram: avaliação, estratégias para atendimento, formação dos docentes, expectativas das familias , criatividade e inteligências múltiplas. Uma discussão necessária e quase ausente dos trabalhos é o estabelecimento de políticas educacionais para o atendimento educacional dos alunos com AH/SD.

O baixo índice de publicações científicas sobre o tema encontrado em nosso estudo confirmam os resultados encontrados nos levantamentos realizados por Pérez e Freitas (2009, 2012), Anjos (2011), Freitas, Hosda e Costa (2014) e Rambo e Fernandes (2020). A escassez de produção científica dá continuidade à prevalência de mitos e crenças populares relativas às pessoas com AHSD:

O pensamento corrente de que esses alunos não precisam ter atendimento especial; que são sempre os alunos 'nota dez' da sala de aula; que só existem em classes privilegiadas (uma crença antiga que as pesquisas do mundo inteiro já têm jogado por terra) soma-se ao sentimento de culpa e de pena pelos alunos com deficiência, que os coloca em posição desprivilegiada. (Pérez e Freitas, 2009, p. 12).

Para as autoras a maior produção e divulgação de conhecimentos sobre o tema podem ajudar a superar os mitos e crenças, a invisibilidade dos alunos com AH/SD e a falta de estratégias reais de inclusão.

Ao analisar as publicações em dois periódicos qualificados da área de educação especial, Freitas, Hosda e Costa (2014) constataram que de 2001 a 2013 foram publicados somente 34 artigos sobre o tema. As autoras assim questionam se a baixa produção científica em AH/SD se deveria ao baixo número de pesquisas defendidas nas universidades ou ao pouco interesse pela temática, pois como aponta a literatura é preterida em prol das deficiências.

O que leva a esse resultado? O baixo número de pesquisas defendidas nas universidades brasileiras nesta temática? $\mathrm{O}$ baixo interesse pela temática uma vez que há como aponta a literatura um interesse maior pelas deficiências? (Freitas, Hosda e Costa, 2014, p. 78).

As autoras pontuam ainda a necessidade de exploração de aspectos peculiares relacionados à superdotação como criatividade, precocidade e genialidade, de questões relacionadas ao papel da família, bem como uma especial atenção para a categoria das $\mathrm{AH} / \mathrm{SD}$ associadas a outras especificidades educacionais. 
A ampliação do debate sobre o tema promoverá maior interesse e aumentará o volume das pesquisas e publicações, possibilitando maior acesso aos profissionais da educação, às famílias dos alunos e comunidade em geral. E, desse modo, poderão ser delineadas novas possibilidades de caminhos realmente inclusivos para o alunado com AH/SD.

\section{Considerações Finais}

Os dados aqui apresentados e discutidos resultam de uma pesquisa realizada com o intuito de verificar como o tópico Altas habilidades/Superdotação vem sendo estudado em programas de pós-graduação brasileiros no período de 2002 e 2020. Os dados foram colhidos nos trabalhos catalogados no banco de dados da Biblioteca Digital Brasileira de Teses e Dissertações.

Os resultados confirmam que apesar de constituir o público-alvo da educação especial, a área de AH/SD continua carente de estudos e práticas ancorados na perspectiva de educação inclusiva. As matrículas desse alunado são ínfimas se comparadas com as projeções da Organização Mundial de Saúde para essa população; dentre as causas prováveis destacam-se a falta de políticas educacionais bem definidas e efetivas.

A análise dos dados colhidos indicou a necessidade de ampliação de pesquisas sobre especificidades relacionadas à aprendizagem e desenvolvimento das pessoas com AH/SD, bem como a sua associação com outras necessidades educacionais especiais.

Afora a escassez de estudos, constatamos ainda que eles são mais escassos em algumas regiões do país, fato determinante para o desconhecimento ainda maior na nesses locais; maior, então, a invisibilidade das pessoas com AH/SD.

É urgente reconhecer, de fato, que o aluno com AH/SD compõe o público-alvo da política nacional de educação inclusiva, identificar suas caracteristicas de aprendizagem e desenvolvimento, mapear a população escolar e para ela delinear caminhos mais efetivos e inclusivos de escolarização. É essencial a realização de pesquisas que abordem este temas e que elas sejam divulgadas em veículos e contextos acessíveis aos professores e demais profissionais relacionados com o contexto escolar, bem como à comunidade em geral.

\section{Referências}

Anjos, I. R. S. (2011). Dotação e talento: concepções reveladas em dissertações e teses no Brasil. (Tese de Doutorado). Universidade Federal de São Carlos, Programa de Pós-Graduação em Educação Especial, São Carlos.

BDTD. (2021). Biblioteca digital de teses e dissertações. https://bdtd.ibict.br/vufind/.

Delou, C. M. C. (2007). Educação do aluno com altas habilidades/superdotação: legislação e políticas educacionais para a inclusão. In D. S. Fleith (Org.) A construção de práticas educacionais para alunos com altas habilidade/superdotação (p. 25-40). Brasília: Ministério da Educação, Secretaria de Educação Especial.

Freitas, S. N., Hosda, C. B. K. \& Costa, L. C. (2014). A produção científica em altas habilidades/superdotação nas revistas brasileiras de educação especial. Revista Diálogos e Perspectivas em Educação Especial, 1(1), 75-84.

Ferreira, N. S. (2002). As pesquisas denominadas “estados da arte”. Educação e Sociedade, ano XXIII, 23(79), $257-272$.

Goulart, A. M. P. L., Mori, N. N. R., Mesti, R. L., Albuquerque, R. A.\& Brandão, S. H. A. (2016). Altas habilidades/superdotação: reflexões e processo educacional. (2a ed.), EDUEM.

INEP. Instituto Nacional de Estudos e Pesquisas Educacionais Anísio Teixeira. (2016). Resumo técnico: censo da educação básica. Brasília.

Lei 9394, de 20 de novembro de 1996. (1996). Diário Oficial da União. https://www2.camara.leg.br/legin/fed/lei/1996/lei-9394-20-dezembro-1996-362578publicacaooriginal-1-pl.html.

Matos, B. C. \& Maciel, C. E. (2016.). Políticas Educacionais do Brasil e Estados Unidos para o Atendimento de Alunos com altas Habilidades/superdotação (AH/SD). Revista Brasileira de Educação Especial, 22(2), 175-188.

Mori, N. N. R. \& Brandão, S. H. A. (2009). O atendimento em salas de recursos para alunos com altas habilidades/superdotação: o caso do Paraná. Revista Brasileira de Educação Especial, 15(3), 485-498.

PNEI. (2008). Política Nacional de Educação Especial na perspectiva da educação inclusiva. Brasília: Ministério da Educação.

Pereira, A. S., Shitsuka, D. M., Parreira, F. J. \& Shitsuka, R. (2018). Metodologia da pesquisa científica UFSM. https://repositorio.ufsm.br/bi tstream/handle/1/15824/Lic_Computacao_Metodologia-Pesquisa-Cientifica.pdf?sequence=1. 
Research, Society and Development, v. 10, n. 2, e43010212715, 2021

(CC BY 4.0) | ISSN 2525-3409 | DOI: http://dx.doi.org/10.33448/rsd-v10i2.12715

Pérez, S. G. P. B. \& Freitas, S. N. (2012). Altas habilidades/superdotação: atendimento especializado. ABPEE.

Pérez, S. G. P. B. \& Freitas, S. N. (2016). Manual de identificação de altas habilidades/superdotação. Apprehendere.

Pérez, S. G. P. B. \& Freitas, S. N. (2009). Estado do conhecimento na área de altas habilidades/superdotação no Brasil: uma análise das últimas décadas. In Anais, 32 ${ }^{a}$. Reunião Anual da Anped (p. 1-13), Caxambú. http://32reuniao.anped.org.br/arquivos/trabalhos/GT15-5514--Int.pdf.

Rambo, M. C. D. \& Fernandes, S. A. A. (2020). Uma revisão bibliográfica sobre as altas habilidades/superdotação com enfoque em matemática. Revista Brasileira de Ensino de Ciência e Tecnologia, 13(2), 78-105.

Renzulli, J. S. (2004). O que é essa coisa chamada superdotação, e como a desenvolvemos? Uma retrospectiva de vinte e cinco anos. Revista Educação, 52(1), $75-131$.

Severino, A. J. (2016). Metodologia do trabalho científicoCortez.

Virgolim, A. M. R. (2014). A contribuição dos instrumentos de investigação de Joseph Renzulli para a identificação de estudantes com Altas habilidades/superdotação. Revista Brasileira de Educação Especial, 27 (50), 581-609. 